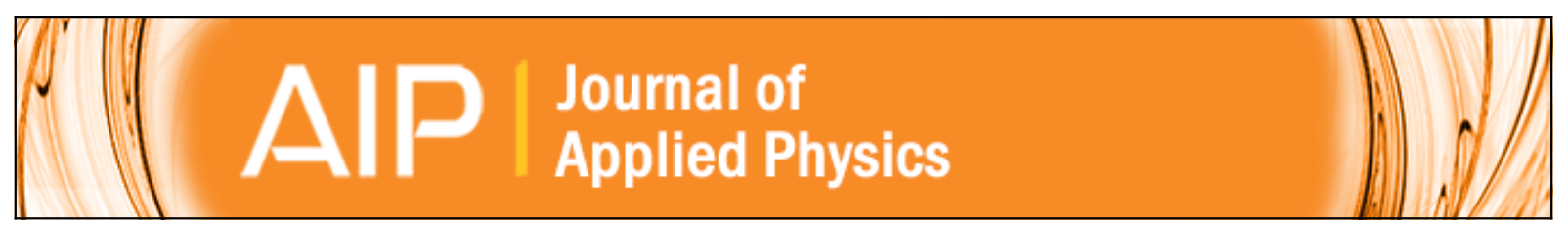

\title{
Formation kinetics of trivacancy-oxygen pairs in silicon
}

N. Ganagona, L. Vines, E. V. Monakhov, and B. G. Svensson

Citation: Journal of Applied Physics 116, 124510 (2014); doi: 10.1063/1.4896066

View online: http://dx.doi.org/10.1063/1.4896066

View Table of Contents: http://scitation.aip.org/content/aip/journal/jap/116/12?ver=pdfcov

Published by the AIP Publishing

\section{Articles you may be interested in}

Oxygen aggregation kinetics, thermal donors and carbon-oxygen defect formation in silicon containing carbon and tin

J. Appl. Phys. 118, 015704 (2015); 10.1063/1.4923388

Transformation of divacancies to divacancy-oxygen pairs in p-type Czochralski-silicon; mechanism of divacancy diffusion

J. Appl. Phys. 115, 034514 (2014); 10.1063/1.4862435

Donor levels of the divacancy-oxygen defect in silicon

J. Appl. Phys. 115, 012004 (2014); 10.1063/1.4837995

In-growth of an electrically active defect in high-purity silicon after proton irradiation

J. Appl. Phys. 114, 223706 (2013); 10.1063/1.4841175

Deep levels in high-energy proton-irradiated tin-doped n-type Czochralski silicon

Appl. Phys. Lett. 76, 2838 (2000); 10.1063/1.126490

\section{AIP Journal of Applied Physics \\ INTRODUCING INVITED PERSPECTIVES Ultrafast magnetism and $\mathrm{THz}$ spintronics Authors: Jakob Walowski and Markus Münzenberg}




\title{
Formation kinetics of trivacancy-oxygen pairs in silicon
}

\author{
N. Ganagona, ${ }^{\text {a) }}$ L. Vines, E. V. Monakhov, and B. G. Svensson \\ Department of Physics, Center for Materials Science and Nanotechnology, University of Oslo, P.O. Box 1048, \\ Blindern, N-0316 Oslo, Norway
}

(Received 12 August 2014; accepted 8 September 2014; published online 25 September 2014)

\begin{abstract}
The formation of donor and acceptor states of the trivacancy-oxygen $\left(V_{3} \mathrm{O}\right)$ complex in $\mathrm{p}$ - and $\mathrm{n}$ type silicon, respectively, has been studied in detail by means of deep level transient spectroscopy. The samples were irradiated with $1.8 \mathrm{MeV}$ protons, and it was found that acceptor and donor states of $V_{3}$ disappear at annealing temperatures below $200^{\circ} \mathrm{C}$, with a transition from the metastable (110) planar configuration to the stable fourfold coordinated configuration. Annealing above $200{ }^{\circ} \mathrm{C}$ unveils the formation of two levels with energy positions at $E_{c}-0.34 \mathrm{eV}$ and $E_{c}-0.46 \mathrm{eV}$ in n-type samples and two levels at $E_{v}+0.24 \mathrm{eV}$ and $E_{v}+0.11 \mathrm{eV}$ in p-type samples. ( $E_{c}$ and $E_{v}$ denote the conduction and valence band edge, respectively.) The amplitudes of these levels show an almost one-to-one correlation with those of the $V_{3}$-related levels occurring after irradiation. In accordance with recent reports in the literature, the emerging levels are ascribed to the $V_{3} \mathrm{O}$ complex; single and double negative charge states in n-type samples and single and double positive charge states in p-type samples. By undertaking isothermal formation of the $V_{3} \mathrm{O}$ complex in p-type samples which exhibits first-order kinetics, the diffusivity of $V_{3}$ in the neutral charge state is determined to be $(8.5 \pm 3.5) \times 10^{-2} \exp [-(1.50 \pm 0.04) \mathrm{eV} / \mathrm{kT}] \mathrm{cm}^{2} / \mathrm{s}$. C 2014 AIP Publishing LLC.

[http://dx.doi.org/10.1063/1.4896066]
\end{abstract}

\section{INTRODUCTION}

Vacancy related defects in silicon influence the electrical and optical properties and can serve as efficient recombination centers reducing the minority charge carrier lifetime. Thus, understanding of the properties of these defects is important for Si-based devices, like, for example, solar cells. Among the multi-vacancy complexes $\left(V_{n}\right)$, only the divacancy $\left(V_{2}\right)$ has been thoroughly studied using several techniques, ${ }^{1-4}$ while $V_{n}$ with $\mathrm{n}>2$ have been studied to a much lesser extent. ${ }^{5}$

Recently, there has been a growing interest towards the trivacancy $\left(V_{3}\right)$ and related complexes. ${ }^{6,7}$ In an early electron paramagnetic resonance (EPR) study on neutron irradiated samples, a spectrum labeled $A 4$ was assigned to $V_{3}$ in a (110) planar configuration. $^{8}$ It was shown that A4 disappeared upon isochronal annealing in the temperature range of $250-300^{\circ} \mathrm{C}$, i.e., in the range similar to $V_{2}{ }^{9}$ In a Deep level transient spectroscopy (DLTS) study by Ahmed et al., ${ }^{5}$ levels with energy positions of $\sim E_{c}-0.46 \mathrm{eV}$ and $\sim E_{c}-0.36 \mathrm{eV}$ were tentatively assigned to single and double acceptor states of the $V_{3}$ center, where $E_{c}$ denotes the conduction band edge. However, it was found that these levels disappeared in the temperature range of $50-100^{\circ} \mathrm{C}$, which contradicted the anticipated stability of the $V_{3}$ center. Recently, in a combined DLTS and ab-initio study, Markevich et al. ${ }^{6}$ found that $V_{3}$ is a bi-stable defect with two configurations: fourfold coordinated (FFC) and metastable (110) planar. ${ }^{6,7} V_{3}$ in the (110) planar configuration occurs in the charge states with energy levels at $\sim E_{c}-0.36 \mathrm{eV}$, $\sim E_{c}-0.46 \mathrm{eV}, \sim E_{v}+0.19 \mathrm{eV}$, and $\sim E_{v}+0.105 \mathrm{eV}$, where $E_{v}$ denotes the valence band edge. These levels are attributed

${ }^{a)}$ Electronic mail: naveengoud.ganagona@fys.uio.no to doubly negative $(=/-)$, negative $(-/ 0)$, positive $(+/ 0)$, and doubly positive $(2+/+)$ transitions of $V_{3}$, respectively. The FFC structure is, however, the lowest in energy and has the only acceptor state at $E_{c}-0.075 \mathrm{eV}$. In n-type samples, it has been observed that the transformation from single and double acceptor states of $V_{3}$ in the planar configuration to the stable FCC structure occurs in the temperature range of $50-120^{\circ} \mathrm{C},{ }^{6}$ consistent with the results from the previous studies of these two energy levels, ${ }^{5,10}$ where Bleka et al. ${ }^{10}$ also demonstrated a close one-to-one proportionality between their amplitudes.

The concentration of $V_{3}$ is strongly enhanced after high energy particle irradiation and/or ion implantation. In n-type samples, it was found that $V_{3}$ starts to migrate above $200{ }^{\circ} \mathrm{C}$ with an activation energy of $1.47 \pm 0.04 \mathrm{eV} .{ }^{11}$ The study suggested that $V_{3}$ would anneal slower in epitaxial samples compared to Czochralski $(\mathrm{Cz})$ ones due to the lower impurity content. One of the most abundant impurities in $\mathrm{Cz}-\mathrm{Si}$ is interstitial oxygen $\left(O_{i}\right)$, and trivacancy-oxygen interaction has been suggested to be the main mechanism of $V_{3}$ elimination upon the annealing. 6,11

It was reported in Ref. 6 that isochronal annealing of electron irradiated n-type material in the temperature range of $200-300^{\circ} \mathrm{C}$ resulted in the disappearance of the $V_{3}$ related levels and concurrent formation of two new levels at $E_{c}-0.34 \mathrm{eV}$ and $E_{c}-0.455 \mathrm{eV}$ with an amplitude similar to those of $V_{3}$. The new levels were assigned to doubly negative and singly negative states of the trivacancy-oxygen $\left(V_{3} \mathrm{O}\right)$ centers in (110) planar configuration. In p-type material, however, a detailed qualitative study of the transformation kinetics of $V_{3}$ to $V_{3} \mathrm{O}$ has not been undertaken. Markevich et $a .^{7}$ observed a shift in the position of the $V_{2}(+/ 0)$ peak during annealing, and it was discussed that the emerging level is a combination of $V_{2} \mathrm{O}(+/ 0)$ and $V_{3} \mathrm{O}(+/ 0)$. In the 
same study, a level at $E_{v}+0.12 \mathrm{eV}$ was observed upon the $V_{3}(2+/+)$ annealing and tentatively identified as $V_{3} \mathrm{O}(2+/$ + ). In Ref. 12, two levels at $E_{v}+0.24 \mathrm{eV}$ and $E_{v}+0.11 \mathrm{eV}$ levels were resolved after annealing of proton-irradiated ptype $\mathrm{Cz}$ samples, supporting their assignment as the single and double donor states of $V_{3} \mathrm{O}$, respectively, made in Ref. 7 .

In the present work, we report on the formation kinetics of $V_{3} \mathrm{O}$ in p- and n-type $\mathrm{Si}$ irradiated with $1.8 \mathrm{MeV}$ protons. The kinetics is of first order and by extracting the temperature-dependent rate of the formation of $V_{3} \mathrm{O}$, the activation energy and the frequency factor of the processes are found to be $1.50 \pm 0.04 \mathrm{eV}$ and $2.1 \pm 0.7 \times 10^{10} \mathrm{~s}^{-1}$, respectively. The former is attributed to the migration energy of $V_{3}$ and applying the theory for diffusion-limited reactions; the latter yields a pre-exponential factor of $\sim 8 \times 10^{-2} \mathrm{~cm}^{2} / \mathrm{s}$ for the $V_{3}$ diffusivity.

\section{EXPERIMENTAL DETAILS}

$\mathrm{p}^{+} \mathrm{n}^{-} \mathrm{n}^{+}$and $\mathrm{n}^{+} \mathrm{p}$ diodes were fabricated on phosphorous and boron doped wafers, respectively. The $\mathrm{p}^{+} \mathrm{n}^{-} \mathrm{n}^{+}$samples were prepared from a silicon wafer having a highly phosphorus-doped $\left(\mathrm{n}^{+}\right)$substrate with a lightly $\mathrm{n}$-doped $\left(\mathrm{n}^{-}\right)$ epitaxial layer grown on the front surface. These epi-wafers were subsequently processed into pads of $\mathrm{p}^{+} \mathrm{n}^{-} \mathrm{n}^{+}$diodes. The $\mathrm{p}^{+}$-layer was realized by ion implantation of boron with post-implant annealing. The thickness of the epitaxial nlayer was $\sim 20 \mu \mathrm{m}$ and the doping concentration, $N_{d}$, in the layer was about $\sim 3 \times 10^{13} \mathrm{~cm}^{-3}$. The $\mathrm{n}^{+} \mathrm{p}$ diodes were prepared using $\mathrm{Cz}$ wafers with a boron concentration of $\sim 1 \times 10^{15} \mathrm{~cm}^{-3}$. First, the wafers were dry oxidized at $1100^{\circ} \mathrm{C}$ for $3 \mathrm{~h}$ to grow a $250 \mathrm{~nm}$ thick $\mathrm{SiO}_{2}$ layer. The $\mathrm{n}^{+}$ layer was formed by in-diffusion of phosphorous (P) from gas phase in a quartz tube. Aluminum ( $\mathrm{Al})$ Ohmic contacts were prepared by thermal evaporation on the front side $\left(\mathrm{n}^{+}\right.$ or $\mathrm{p}^{+}$side) and silver paste was used as contact on the backside for both sets of samples. The oxygen [O] and carbon [C] concentration in the epi-layer of the $\mathrm{p}^{+} \mathrm{n}^{-}-\mathrm{n}^{+}$samples were $\sim(2-3) \times 10^{17}$ and $\leq 2 \times 10^{16} \mathrm{~cm}^{-3}$, respectively, while in the $\mathrm{n}^{+} \mathrm{p}$ samples they were $\sim 4 \times 10^{17}$ and $\leq 2 \times 10^{16} \mathrm{~cm}^{-3}$, respectively, as determined by secondary ion mass spectrometry (SIMS).

Irradiation of the diodes was performed at room temperature (RT) with $1.8 \mathrm{MeV}$ protons to a dose of $(2-5) \times 10^{12} \mathrm{~cm}^{-2}$ and $3 \times 10^{10} \mathrm{~cm}^{-2}$ for the $\mathrm{n}^{+} \mathrm{p}$ and $\mathrm{p}^{+} \mathrm{n}^{-}$$\mathrm{n}^{+}$type samples, respectively. The projected range of the protons was $\sim 40 \mu \mathrm{m}$, as estimated by simulations using the TRIM code, ${ }^{13}$ and far beyond the extension of the region probed in the DLTS measurements $(\sim 1-10 \mu \mathrm{m})$. Isochronal annealing (30 min duration) was carried out for temperatures in the range of $200-300^{\circ} \mathrm{C}$, while isothermal annealing was carried out at five different temperatures $\left(200^{\circ} \mathrm{C}, 225^{\circ} \mathrm{C}\right.$, $250{ }^{\circ} \mathrm{C}, 275^{\circ} \mathrm{C}$, and $300^{\circ} \mathrm{C}$ ). During the annealing, outdiffusion of $\mathrm{H}$ from the region around the projected range may be anticipated, but no indications of any H-related levels in the DLTS spectra were found.

The DLTS measurements were carried out by employing a refined version of the set-up described in Ref. 14. The reverse bias quiescent voltage was kept at $10 \mathrm{~V}$ and during the filling pulse $(50 \mathrm{~ms}$ duration) the bias was $0 \mathrm{~V}$. The temperature was scanned between 40 and $300 \mathrm{~K}$, and eight DLTS spectra with rate windows from $5 \mathrm{~ms}^{-1}$ to $640 \mathrm{~ms}^{-1}$ were extracted applying both a lock-in and a high resolution weighting function (GS4). ${ }^{15}$

\section{RESULTS AND DISCUSSION}

Figure 1 shows DLTS spectra of an as-irradiated $\mathrm{p}^{+} \mathrm{n}^{-}-\mathrm{n}^{+}$sample, and after annealing at $200^{\circ} \mathrm{C}$ and $300^{\circ} \mathrm{C}$. In the as-irradiated sample, three major peaks with energy level positions at $E_{c}-0.44 \mathrm{eV}, E_{c}-0.23 \mathrm{eV}$, and $E_{c}-0.18 \mathrm{eV}$ are observed and identified as the single acceptor state of $V_{2}(-/ 0)$, double acceptor state of $V_{2}(=/-)$, and the acceptor state of the vacancy-oxygen $(V O)$ pair. In addition, the as-irradiated sample reveals a level at $E_{c}-0.36 \mathrm{eV}$, labeled as $V_{3}(=/-)$ in accordance with Ref. 6

The amplitude of the DLTS peak around $V_{2}(-/ 0)$ is larger than that of $V_{2}(=/-)$ which indicates the presence of other levels closely overlapping with $V_{2}(-/ 0)$. One potential candidate is the acceptor state of the vacancy-phosphorus $(V P)$ pair. However, VP is expected to be very minute in the present samples due to the low concentration of $\mathrm{P}$ and high concentration of $\mathrm{O}$ with a difference by four orders of magnitude; $\mathrm{O}$ and $\mathrm{P}$ are the main and competing traps for migrating mono-vacancies and in the following $\mathrm{VP}$ is neglected. ${ }^{16}$ However, as previously reported, ${ }^{6,10} V_{3}(=/-)$ and $V_{3}(-/ 0)$ are expected to have energy level positions around $E_{c}-0.36 \mathrm{eV}$ and $E_{c}-0.45 \mathrm{eV}$, respectively, i.e., $V_{3}(-/ 0)$ will overlap with $V_{2}(-/ 0)$. Indeed, $V_{3}(=/-)$ (arising from the (110) planar configuration) disappears after the heattreatment at $200^{\circ} \mathrm{C}$ for $20 \mathrm{~min}$, and at the same time, a decrease in the $V_{2}(-/ 0)$ peak occurs although $V_{2}$ remains stable as illustrated by the amplitude of the $V_{2}(=/-)$ peak. Moreover, the reduced concentration of the $V_{2}(-/ 0)$ peak is close to the concentration of $V_{3}(=/-)$ in the as-irradiated sample. Hence, the deviation between $V_{2}(-/ 0)$ and $V_{2}(=/-)$ is mainly ascribed to the contribution of $V_{3}(-/ 0)$. Simultaneously, a new level emerges at $E_{c}-0.075 \mathrm{eV}$ with the disappearance of $V_{3}(=/-)$ and $V_{3}(-/ 0)$, and its amplitude is almost equal to that of the $V_{3}$ levels, corroborating the identification of the $E_{c}-0.075 \mathrm{eV}$ level as a single acceptor state of $V_{3}$ in the stable FFC configuration. ${ }^{6}$



FIG. 1. DLTS spectra of n-type samples $\left(\mathrm{p}^{+} \mathrm{n}^{-}-\mathrm{n}^{+}\right)$as-irradiated, after heattreatment at $200^{\circ} \mathrm{C}$ for $20 \mathrm{~min}$ and $300{ }^{\circ} \mathrm{C}$ for $45 \mathrm{~min}$ duration. The lock-in weighting function is used and the rate window is $(40 \mathrm{~ms})^{-1}$. 
After heat-treatment at $300^{\circ} \mathrm{C}$ for $45 \mathrm{~min}$, a shift in the $V_{2}$ peaks takes place and new levels identified as $V_{2} \mathrm{O}$ levels occur. ${ }^{3,4,17}$ However, the amplitude of the $V_{2} \mathrm{O}(-/ 0)$ level is larger than that of $V_{2}(-/ 0)$, which can be attributed to the formation of an additional level with similar position as $V_{2} \mathrm{O}(-/ 0)$. In parallel to the shift in temperature of the $V_{2}(-/ 0)$ peak, $V_{3}$ in the FFC configuration anneals out with the formation of a new level at $E_{c}-0.34 \mathrm{eV}$ labeled as $V_{3} \mathrm{O}(=/-)$. The difference between the amplitudes of the $V_{2} \mathrm{O}(-/ 0)$ and $V_{2} \mathrm{O}(=/-)$ peaks is almost the same as the amplitudes of the $E_{c}-0.075 \mathrm{eV}$ ( $V_{3}$ in FFC configuration) and $E_{c}-0.34 \mathrm{eV}$ levels. These two new levels $\left(E_{c}-0.34 \mathrm{eV}\right.$ and the one contributing to the $V_{2}(-/ 0)$ peak) are assigned to the single and double acceptor states of $V_{3} \mathrm{O}$, respectively, in accordance with the results in Ref. 6. The intensity of the $V_{3} \mathrm{O}$ levels is about $25 \%-30 \%$ of that of the $V_{2}$ and $V_{2} \mathrm{O}$ levels, and in conclusion, our results for the n-type samples show very similar behavior to those reported previously by Markevich et al. ${ }^{6}$ and support the suggestion of single and double acceptor states of $V_{3} \mathrm{O}$ at $E_{c}-0.34 \mathrm{eV}$ and $E_{c}-0.45 \mathrm{eV}$, respectively.

Figure 2 shows DLTS spectra of as-irradiated p-type samples $\left(\mathrm{n}^{+} \mathrm{p}\right.$ diodes), after annealing at $200^{\circ} \mathrm{C}$ and $300^{\circ} \mathrm{C}$. In the as-irradiated sample, two major peaks appear at $E_{v}+0.19 \mathrm{eV}$ and $E_{v}+0.36 \mathrm{eV}$ and are identified as single donor states of $V_{2}$ and the interstitial carbon-interstitial oxygen $\left(C_{i} O_{i}\right)$ pair, respectively. ${ }^{18}$ In addition, the spectrum of the as-irradiated sample reveals two additional levels with positions at $E_{v}+0.10 \mathrm{eV}$ and $E_{v}+0.09 \mathrm{eV}$, labeled as $V_{3}(2+/+)$ and $H 1$, respectively.

As the DLTS measurements were done $24 \mathrm{~h}$ after the irradiation, no levels associated with interstitial carbon $\left(C_{i}\right)$ are observed, consistent with previous reports in the literature. ${ }^{19}$ Further, the $C_{i} O_{i}$ peak is broad and contains a second level positioned at $E_{v}+0.35 \mathrm{eV}$, which completely transforms into $C_{i} O_{i}$ after the heat-treatment at $200^{\circ} \mathrm{C}$. This observation is also consistent with previous studies on irradiated p-type samples and the $E_{v}+0.35 \mathrm{eV}$ level is proposed to arise from a metastable configuration of $C_{i} O_{i}\left(C_{i} O_{i}^{*}\right) .^{20,21}$

The $E_{v}+0.10 \mathrm{eV}\left(V_{3}(2+/+)\right)$ level anneals out after the heat-treatment at $200{ }^{\circ} \mathrm{C}$ for $20 \mathrm{~min}$. At the same time, a decrease in the $V_{2}$ peak takes place although $V_{2}(+/ 0)$ is

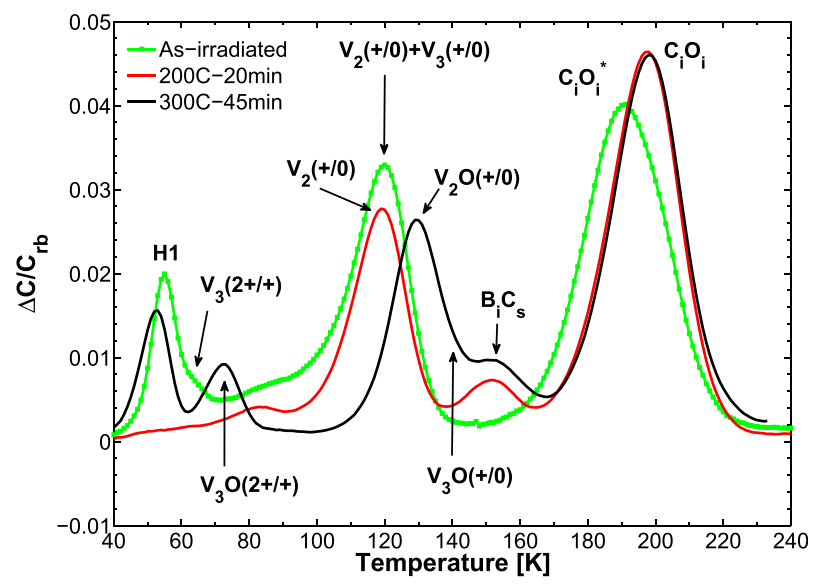

FIG. 2. DLTS spectra of p-type sample as-irradiated, after heat-treatment at $200^{\circ} \mathrm{C}$ for $20 \mathrm{~min}$ and $300^{\circ} \mathrm{C}$ for $45 \mathrm{~min}$ duration. The lock-in weighting function is used and the rate window is $(20 \mathrm{~ms})^{-1}$. known to be stable up to temperatures above $200^{\circ} \mathrm{C}$, as previously discussed. The loss in the $E_{v}+0.19 \mathrm{eV}$ level amplitude equals the amplitude of the $E_{v}+0.10 \mathrm{eV}$ level in the as-irradiated sample. Recently, a similar observation was made by Markevich et al. ${ }^{7}$ and they ascribed the $E_{v}+0.19 \mathrm{eV}$ and $E_{v}+0.10 \mathrm{eV}$ levels to the single and double donor states of $V_{3}$ in the planar (110) configuration. ${ }^{7}$ Here, it should also be emphasized that the thermal evolution of the $E_{v}+0.19 \mathrm{eV}$ and $E_{v}+0.10 \mathrm{eV}$ levels exhibits a close resemblance with that of the acceptor states of the $V_{3}$ planar configuration in the ntype samples. A detailed study on the identification of the $\mathrm{H} 1$ $\left(E_{v}+0.09 \mathrm{eV}\right)$ level is given in Ref. 22 and no further discussion is made here. This holds also for the $E_{v}+0.29 \mathrm{eV}$ level, attributed to a interstitial boron-substitutional carbon $\left(B_{i} C_{s}\right)$ center, ${ }^{23}$ which appears after $200^{\circ} \mathrm{C}$ treatment.

During isothermal annealing of the p-type samples, a gradual transformation from $V_{2}(+/ 0)$ to $V_{2} \mathrm{O}(+/ 0)$ with a one-to-one proportionality occurs and a detailed kinetics analysis is given in Ref. 24. In parallel, defects with levels at $E_{v}+0.24 \mathrm{eV}$ and $E_{v}+0.11 \mathrm{eV}$ appear after the $300^{\circ} \mathrm{C}$ annealing, as shown in Fig. 2; Markevich et al. ${ }^{7}$ have ascribed these levels to single and double donor states of $V_{3} \mathrm{O}$. The amplitudes of these two levels are identical and increase gradually with annealing time, as shown in Fig. 3(a) for isothermal treatment at $300^{\circ} \mathrm{C}$. Further, the final (maximum) concentration of these levels shows a close to one-toone correlation with the $V_{3}$ concentration directly after irradiation in non-annealed samples.

Fig. 3(b) shows the evolution of $V_{3} \mathrm{O}$ as a function of time for all the temperatures studied and the formation can be described by the relation

$$
\left[V_{3} O\right]=\left[V_{3}\right]-\left[V_{3}\right] e^{-c(T) t},
$$

where $\left[V_{3}\right]$ is the initial concentration in the as-irradiated samples, $\left[V_{3} \mathrm{O}\right]$ is the concentration of $V_{3} \mathrm{O}$, and $\mathrm{c}(\mathrm{T})$ is a temperature dependent rate constant.

Fig. 4 shows the Arrhenius plot of $\mathrm{c}(\mathrm{T})$, and $\mathrm{c}(\mathrm{T})$ exhibits a thermally activated behavior described by

$$
c(T)=c_{0} e^{\frac{-E_{a}}{k T}},
$$

where $E_{a}$ is the activation energy, $c_{0}$ is the frequency factor, $\mathrm{T}$ is the absolute temperature, and $\mathrm{k}$ is Boltzmann's constant. For both the levels, $V_{3} \mathrm{O}(2+/+)$ and $V_{3} \mathrm{O}(+/ 0), c(\mathrm{~T})$ is closely described by $E_{a}=1.50 \pm 0.04 \mathrm{eV}$ and $c_{0}=2.1 \pm 0.7$ $\times 10^{10} \mathrm{~s}^{-1}$. The value deduced for $E_{a}$ is practically identical to that obtained by Markevich et al. ${ }^{6,11}$ for $V_{3}$ migration in n-type material strongly supporting the relationship between the annealing of $V_{3}$ and the formation of the donor states of $V_{3} \mathrm{O}$ in our p-type samples. The diffusivity of $V_{3}, D_{V 3}$ can be quantitatively estimated from the results in Fig. 4. Applying the theory for diffusion limited reactions, ${ }^{25}$ the following relation for $V_{3} \mathrm{O}$ holds:

$$
\frac{d\left[V_{3} O(t)\right]}{d t}=c(T)\left[V_{3}(t)\right]=4 \pi R D_{V 3}\left[O_{i}\right]\left[V_{3}(t)\right],
$$

where $\mathrm{R}$ is the capture radius for the trapping reaction and $\left[O_{i}\right]$ is the concentration of interstitial oxygen. In Eq. (3), $O_{i}$ 

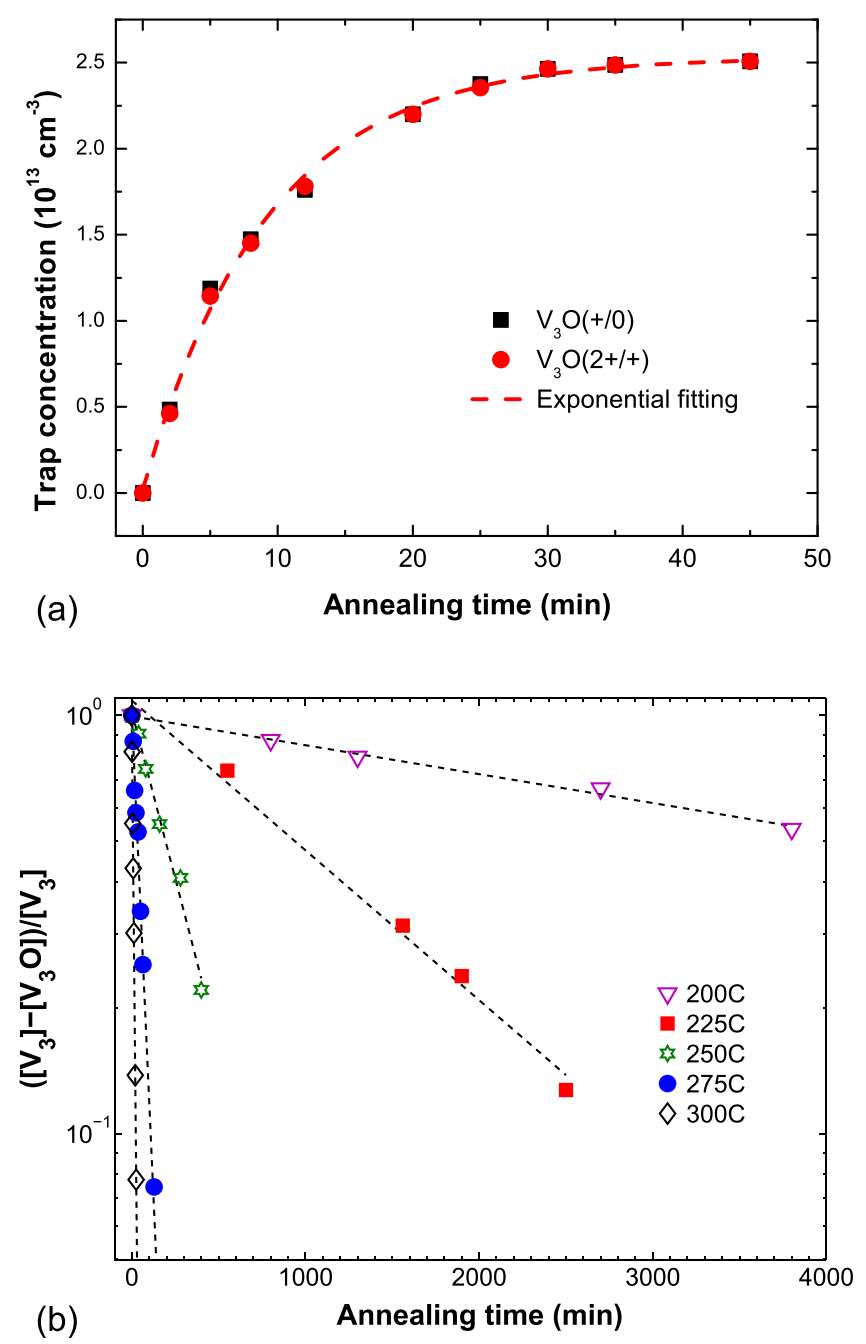

FIG. 3. (a) The amplitudes of the $V_{3} \mathrm{O}(+/ 0)$ and $V_{3} \mathrm{O}(2+/+)$ levels versus time during the isothermal annealing at $300^{\circ} \mathrm{C}$. (b) The difference between the initial concentration of $V_{3}(2+/+)$ and the growing concentration of $V_{3} \mathrm{O}(2+/+)$ during isothermal annealing at $200,225,250,275$, and $300^{\circ} \mathrm{C}$. The values have been normalized to the initial amplitude of $V_{3}$. The dotted lines represent least squares exponential fits to the experimental data.

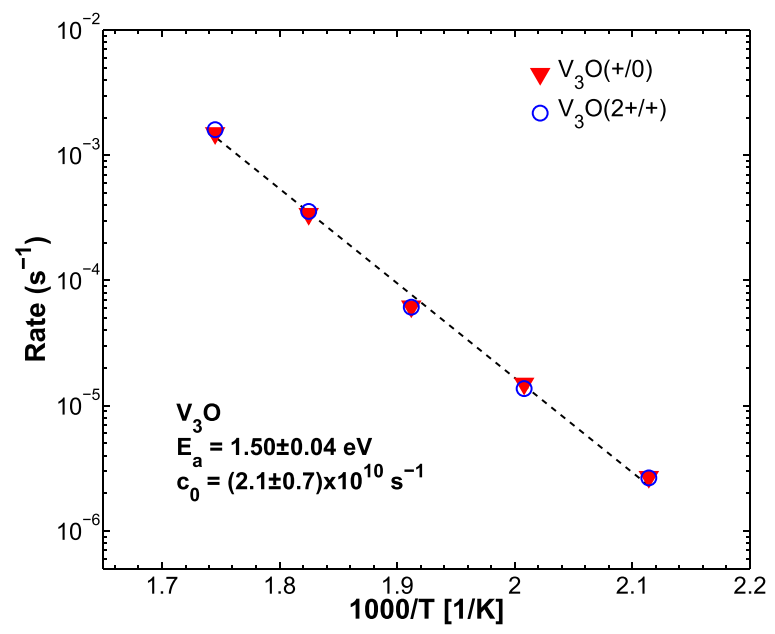

FIG. 4. Arrhenius plot for the formation rate of $V_{3} \mathrm{O}$. The dotted line represents an exponential fit of the rate values. is assumed to be immobile exhibiting a diffusivity of $10^{-23} \mathrm{~cm}^{2} / \mathrm{s}$ in the studied temperature range. ${ }^{26}$ By combining Eqs. (2) and (3) with $D_{V 3}=D_{V 3}^{0} e^{\frac{-E_{a}}{k T}}$, one obtains

$$
D_{V 3}^{0}=\frac{c_{0}}{4 \pi R\left[O_{i}\right]} \text {. }
$$

Putting $\mathrm{R}$ equal to $5 \pm 1 \AA$ (geometrical value) and $\left[O_{i}\right]=4 \pm 1 \times 10^{17} \mathrm{~cm}^{-3} \quad$ (measured value) and using $\mathrm{c}_{0}=(2.1 \pm 0.7) \times 10^{10} \mathrm{~s}^{-1}$, one arrives at $\mathrm{D}_{V 3}^{0}=(8.5 \pm 3.5)$ $\times 10^{-2} \mathrm{~cm}^{2} / \mathrm{s}$.

$V_{3}$ is, similarly to $V_{2}$, an intrinsic defect generated by high-energy particle irradiation, and this could account for its consistent appearance with a ratio about $30 \%$ to the $V_{2}$ concentration in samples irradiated with $1.8 \mathrm{MeV}$ protons. $V_{3}$ is presumably generated directly during the proton irradiation, i.e., the generation does not involve long-distance migration and pairing of $V$ and $V_{2} \cdot{ }^{27} V_{2}$ is estimated to have a threshold displacement energy of $\sim 80 \mathrm{eV}$ (Ref. 27) and assuming a threshold $\sim 180 \mathrm{eV}$ for $V_{3}$, a ratio of $30 \%$ is obtained between the generation rates of $V_{3}$ and $V_{2}$ for 1.8 MeV protons according to TRIM simulations. Such a rather high threshold for the generation of $V_{3}$ is also corroborated by that electron energies above $\sim 5 \mathrm{MeV}$ are required to detect an appreciable concentration of $V_{3}{ }^{6}$

Moreover, the activation energy deduced for $V_{3}$ migration represents the neutral charge state (the Fermi level is close to midgap at the annealing temperatures) and a value $\sim 0.2 \mathrm{eV}$ higher than for migration of the neutral $V_{2}^{24}(\sim 1.5$ versus $\sim 1.3 \mathrm{eV}$ ) appears conceivable considering the larger size of $V_{3}$. It is also interesting to note that $D_{V 3}^{0}$ is substantially larger than $\mathrm{D}^{0}{ }_{\mathrm{V} 2}\left(\sim 8 \times 10^{-2}\right.$ versus $\left.\sim 1.5 \times 10^{-3} \mathrm{~cm}^{2} / \mathrm{s}\right)$, possibly associated with a larger geometrical factor for $V_{3}$ diffusion but further studies need to be pursued to confirm this speculation.

\section{CONCLUSIONS}

Annealing studies of $V_{3}$ and $V_{3} \mathrm{O}$ complexes in proton irradiated $\mathrm{p}$ - and n-type $\mathrm{Si}$ samples have been performed using DLTS. In both types of materials, $V_{3}$ in the (110) planar configurations disappears at temperatures below $200{ }^{\circ} \mathrm{C}$, and a transformation to the stable FFC structure takes place. At temperatures above $200{ }^{\circ} \mathrm{C}$, formation of $V_{3} \mathrm{O}$ is demonstrated and detailed isothermal studies of the p-type samples reveal a process with first-order kinetics having with an activation energy of $1.50 \pm 0.04 \mathrm{eV}$. These results provide firm evidence in favor of a process where migrating $V_{3}$ 's are trapped by immobile oxygen atoms resulting in the formation of $V_{3} \mathrm{O}$ pairs. In both the p- and n-type materials, $V_{3}$ appears in the neutral charge state during the transformation to $V_{3} \mathrm{O}$. Applying the theory for diffusion limited reactions, the diffusivity of $V_{3}$ in the studied p-type samples is determined to be $(8.5 \pm 3.5) \times 10^{-2} \exp [-(1.50 \pm 0.04) \mathrm{eV} / \mathrm{kT}]$ $\mathrm{cm}^{2} / \mathrm{s}$, which represents the neutral charge state of $V_{3}$.

\section{ACKNOWLEDGMENTS}

This work was performed within The Norwegian Research Centre for Solar Cell Technology, a Centre for 
Environmentfriendly Energy Research co-sponsored by the Norwegian Research Council and research and industry partners in Norway.

${ }^{1}$ G. D. Watkins and J. W. Corbett, Phys. Rev. 121, 1001 (1961).

${ }^{2}$ B. G. Svensson, B. Mohadjeri, A. Hallén, J. H. Svensson, and J. W. Corbett, Phys. Rev. B 43, 2292 (1991).

${ }^{3}$ E. V. Monakhov, B. S. Avset, A. Hallén, and B. G. Svensson, Phys. Rev. B 65, 233207 (2002).

${ }^{4}$ M. Mikelsen, E. V. Monakhov, G. Alfieri, B. S. Avset, and B. G. Svensson, Phys. Rev. B 72, 195207 (2005).

${ }^{5}$ M. Ahmed, S. Watts, J. Matheson, and A. Holmes-Siedle, Nucl. Instrum. Methods Phys. Res., Sect. A 457, 588 (2001).

${ }^{6}$ V. P. Markevich, A. R. Peaker, S. B. Lastovskii, L. I. Murin, J. Coutinho, V. J. B. Torres, P. R. Briddon, L. L. Dobaczewski, E. Monakhov, and B. G. Svensson, Phys. Rev. B 80, 235207 (2009).

${ }^{7}$ V. P. Markevich, A. R. Peaker, B. Hamilton, S. B. Lastovskii, L. I. Murin, J. Coutinho, V. J. B. Torres, L. Dobaczewski, and B. G. Svensson, Phys. Status Solidi A 208, 568 (2011).

${ }^{8}$ Y.-H. Lee and J. W. Corbett, Phys. Rev. B 9, 4351 (1974).

${ }^{9}$ J. Corbett, J. Bourgoin, L. Cheng, J. Corelli, Y. Lee, P. Mooney, and C. Weigel, Radiation Effects in Semiconductors, Conference Series Vol. 31 (Inst. Phys., Bristol, London, 1976).

${ }^{10}$ J. H. Bleka, E. V. Monakhov, B. G. Svensson, and B. S. Avset, Phys. Rev. B 76, 233204 (2007).

${ }^{11}$ J. Coutinho, V. P. Markevich, A. R. Peaker, B. Hamilton, S. B. Lastovskii, L. I. Murin, B. J. Svensson, M. J. Rayson, and P. R. Briddon, Phys. Rev. B 86, 174101 (2012).
${ }^{12}$ N. Ganagona, L. Vines, E. V. Monakhov, and B. G. Svensson, Solid State Phenom. 205-206, 213 (2013).

${ }^{13}$ J. B. J. F. Ziegler and U. Littmark, The Stopping and Range of Ions in Solids (Pergamon, New York, 1985).

${ }^{14}$ B. G. Svensson, K.-H. Rydén, and B. M. S. Lewerentz, J. Appl. Phys. 66, 1699 (1989).

${ }^{15}$ A. A. Istratov, J. Appl. Phys. 82, 2965 (1997).

${ }^{16}$ B. G. Svensson, EMIS Datarev. Ser. 20, 763 (1999).

${ }^{17}$ G. Alfieri, E. V. Monakhov, B. S. Avset, and B. G. Svensson, Phys. Rev. B 68, 233202 (2003).

${ }^{18}$ M. T. Asom, J. L. Benton, R. Sauer, and L. C. Kimerling, Appl. Phys. Lett. 51, 256 (1987).

${ }^{19}$ L. Vines, E. V. Monakhov, A. Y. Kuznetsov, R. Kozkowski, P. Kaminski, and B. G. Svensson, Phys. Rev. B 78, 085205 (2008).

${ }^{20} \mathrm{~K}$. Abdullin, B. Mukashev, M. Tamendarov, and T. Tashenov, Phys. Lett. A 144, 198 (1990).

${ }^{21}$ L. Makarenko, M. Moll, J. Evans-Freeman, S. Lastovski, L. Murin, and F. Korshunov, Physica B 407, 3016 (2012).

${ }^{22}$ N. Ganagona, L. Vines, E. V. Monakhov, B. G. Svensson, V. P. Markevich, A. R. Peaker, B. Hamilton, V. E. Gusakov, S. B. Lastovskii, and L. I. Murin, in EMRS Spring Meeting (2014).

${ }^{23}$ L. C. Kimerling, M. Asom, J. Benton, P. Drevinsky, and C. Caefer, Mater. Sci. Forum 38-41, 141 (1989).

${ }^{24}$ N. Ganagona, L. Vines, E. V. Monakhov, and B. G. Svensson, J. Appl. Phys. 115, 034514 (2014).

${ }^{25}$ T. R. Waite, Phys. Rev. 107, 463 (1957).

${ }^{26}$ M. Stavola, J. R. Patel, L. C. Kimerling, and P. E. Freeland, Appl. Phys. Lett. 42, 73 (1983).

${ }^{27}$ B. G. Svensson and J. L. Lindström, J. Appl. Phys. 72, 5616 (1992). 